\title{
REGIONAL AND RACIAL DIFFERENCES IN LEPROSY
}

A Report made from Statistics from Dr. C. J. Austin, Medical Superintendent, Central Leprosy Hospital, Makogai, Fij..

Makogai, because of the contrast between the indigenous Melanesian patients and the emigrant Indian patients, offers a fruitful field for the study of regional and racial differences in leprosy infection. The leprosarium at Makogai provides treatment 
for the numerous island groups .comprising the Solomon, Gilbert, Samoan, Tonga and Cook islands. The indigenous peoples may be regarded as Melanesian, belonging to the same racial group. The distance between the Gilbert Islands to the north; which lie on the Equator, and the Cook Islands to the S.W. on the 2oth degree of latitude, is some 2,000 miles, and thus climatic and dietetic factors are involved.

The Indian emigrant to Melanesia belongs to a different racial group, having a different dietetic standard. His racial group has had contact with leprosy through the centuries, thus differing from the Melanesian, whose contact is recent. The dietary of the Indian emigrant is richer in protein, fat and vitamins than the Melanesian, whose diet is largely carbohydrate.

A study of the cases at Makogai shews the following interesting figures.

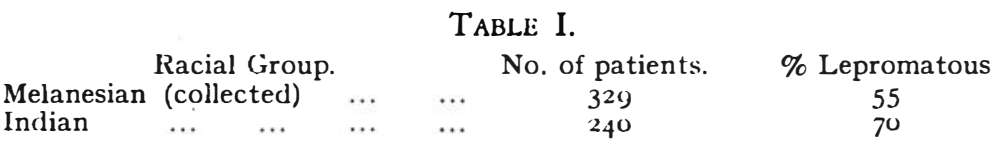

A sub-division of the grouped Melanesians in Table I shews the higher lepromatous type incidence among the Indians more strikingly.

\section{TABLE II.}

Island Group.

Gilbert ...

Samoan

Indian

Fijian $\ldots$

Solomon $\quad \cdots$

Tongan
No. of Cases.

44
47
2.40
127
28
5.3
26

$\%$ Lepromatous.

Standard Error.

$\begin{array}{ll}75 & 6.6 \\ 75 & 6.3 \\ 70 & 3.0 \\ +19 & 4.5 \\ 46 & 9.4 \\ 43 & 6.6 \\ 30 & 9.6\end{array}$

No significant variation can be attributed to climatic differences here. Malnutrition and the high incidence of pulmonary tuberculosis among the Gilbert islanders may be responsible for the high proportion of lepromatous cases, though non random selection of cases sent to Makogai might equally well explain the difference.

The only groups with sufficient numbers to warrant comparison are the Indian and Fijian. Application of the standard error to the Gilbert and Samoan groups shews that their relatively high incidence of lepromatous cases is not significant.

Comparison of the two groups for the years 1934 and 1946 gives:-

\begin{tabular}{llcc}
\multicolumn{2}{c}{ TABLE III. } \\
Year. & (iroup. & No. of Cases. & $\%$ Lepromatous \\
1934 & Fijians & - & 48 \\
& Indians & - & 64 \\
1946 & Fijians & 127 & 49 \\
& Indians & 240 & 70
\end{tabular}


These figures shew that the Indian has a high incidence of lepromatous type leprosy in the Melanesian islands. This is in contrast with the low incidence of lepromatous leprosy in India.

In the tuberculoid form, nothing like the degree of nerve enlargement is seen here as compared with tuberculoid leprosy in India.

\section{Racial Variation in Prognosis.}

The compilation of a table of "improved" cases should reverse the order of Table II. This is, in fact, the case, with a notable exception, the Indian group, which remains at the top of the list.

\begin{tabular}{clcc} 
& \multicolumn{2}{c}{ TABLE IV. } & \\
Year. & Group. & $\%$ Inactive. & $\%$ Improved. \\
& Fijian & 40 & 72 \\
1942 & Indian & 38 & 75 \\
& Cook & 5.3 & 72 \\
& Gilbert & 51 & 64 \\
\hline \multirow{3}{*}{1946} & Tongan & & 65 \\
& Indian & & 57 \\
& Fijian & & 56 \\
& Solomon & & 56 \\
& Cook & & 52 \\
& Gilbert & & 41 \\
& Samoan & & 32
\end{tabular}

Comparison with Table II will shew that the Indian shews appreciably better results under treatment than the Melanesian. Although the incidence of lepromatous leprosy is twice as high amongst Indians as compared with Fijians, the percentage of cases becoming inactive in the two groups is approximately the same.

Racial resistance, if a fact, would appear to enable the Indian to combat the disease rather than prevent it.

\section{SUMIMARY.}

I. The incidence of lepromatous type leprosy amongst Indians in Melanesia would appear to be higher than the incidence of lepromatous leprosy among the Melanesians.

2. The Indian tends to have a better prognosis than the Melanesian, when similar degrees of infection are considered.

3. The geographical factor does not appear to be significant.

4. No evidence is available to assess the importance of the dietetic factor. 